\title{
Design and evaluation of the project and program crashing games
}

DOI:

10.1108/JARHE-07-2017-0083

\section{Document Version}

Accepted author manuscript

Link to publication record in Manchester Research Explorer

\section{Citation for published version (APA):}

Rumeser, D., \& Emsley, M. (2018). Design and evaluation of the project and program crashing games. Journal of Applied Research in Higher Education. https://doi.org/10.1108/JARHE-07-2017-0083

\section{Published in:}

Journal of Applied Research in Higher Education

\section{Citing this paper}

Please note that where the full-text provided on Manchester Research Explorer is the Author Accepted Manuscript or Proof version this may differ from the final Published version. If citing, it is advised that you check and use the publisher's definitive version.

\section{General rights}

Copyright and moral rights for the publications made accessible in the Research Explorer are retained by the authors and/or other copyright owners and it is a condition of accessing publications that users recognise and abide by the legal requirements associated with these rights.

\section{Takedown policy}

If you believe that this document breaches copyright please refer to the University of Manchester's Takedown Procedures [http://man.ac.uk/04Y6Bo] or contact uml.scholarlycommunications@manchester.ac.uk providing relevant details, so we can investigate your claim.

\section{OPEN ACCESS}




\title{
Design and Evaluation of the Project and Program Crashing Games
}

\begin{abstract}
Purpose - This research aims to help project management game designers and educators in simulating complexity in project management games and in assessing the effect of simulated project complexity levels on students' learning experience. To achieve this aim, we attempt to design and evaluate two computer-based project crashing games with different complexity levels, namely Project Crashing Game (PCG) and Program Crashing Game (PgCG).

Design/methodology/approach - A literature review is conducted to identify serious games design principles. These principles are then manifested in the design of PCG and PgCG. The latter is a more complex version of the first. Students' reaction after playing both games are then analyzed quantitatively.

Findings - We discover that students' learning experience is affected by how complex the simulated project is. The more complex the project is (i.e. as in the $\mathrm{PgCG}$ ), the more realistic the game is perceived. Nevertheless, we also discover that the less complex game (PCG) offers significant value to students, particularly to teach basic project management principles to those with minimum or no practical experience. This game is perceived as better in increasing students' learning confidence as its content is perceived as more relevant to their existing knowledge.
\end{abstract}

Originality/value - We adopt a project complexity perspective when designing and evaluating the games.

Keywords Complexity, project management, program management, serious games, gamebased learning, computer-based game

Paper type Research paper

\section{Introduction}

The fact that project management (PM) education struggles in educating project managers and team members to cope with complex problems (Thomas and Mengel, 2008) is ironic as the purpose of PM is about 'making something complex happen' (Martin, 2000b, Dh, 1987). 
Furthermore, there is a significant need for a PM education that educates people not only to 'know what' but also to 'know how' to apply PM knowledge in complex scenarios in their projects (Thomas and Mengel, 2008). The latter signifies the importance of having experience rather than just having knowledge. Both are in fact interrelated as suggested by the basic definition of learning itself (Kolb, 1984, p. 38): 'the process whereby knowledge is created through the transformation of experience'.

Serious games is a potential solution to the issues discussed as these games have 'the advantage of enabling participants to be put into complex, realistic project situations ...' (Al-Jibouri, 2005). However, in current practice, PM serious games designers and educators do not have a clear (or a research-based) guideline on simulating project complexity in their games. Moreover, there is a lack of research to date that could help them in assessing the effect of simulated project complexity level on students' learning experience. Consequently, the effectiveness of the games relies heavily on each designer's or educator's prior knowledge and experience which could negatively affect the reliability and consistency in delivering high quality games for PM education.

To address the problem, this study aims to design two PM games with different project complexity levels and evaluate learners' learning experience after playing both games. The less complex game, namely the Project Crashing Game (PCG), simulates activities crashing (acceleration) in a single project. This single-player game serves as an introductory game before simulating activities crashing in a collection of projects (programs) which are exercised in the more complex multi-player game, namely the Program Crashing Game (PgCG).

Our approach to achieve the aim is by reviewing characteristics of serious games and project complexity in the literature and identifying gaps in current PM serious games studies (Section 2); reviewing serious games design principles in the literature and translating these into PCG and PgCG design (Section 3); identifying measurement methods to evaluate the games (Section 4); developing the games and conducting an experiment whereby students' learning experience with the less complex PM game (i.e. PCG) and the more complex PM game (i.e. PgCG) are analyzed (Section 5); discussing the findings (Section 6); concluding the research and discussing potential implications (Section 7); and suggesting areas for improvement (Section $8)$. 


\section{Literature Review}

\subsection{Characteristics of Serious Games}

Serious games are developed for educational and behavior change purposes (Connolly et al., 2012) and not only for entertainment purposes (Hendrix et al., 2016). These games assist learners to understand a particular subject, help them in acquiring new skills, and expand their existing concepts (Dempsey et al., 1996). By playing the games, learners can experience a simulated real world problem (Calderón and Ruiz, 2015) without exposure to the costs and risks associated with it (Dantas et al., 2004). Serious games can be played with multiple players, such as the Virtual Construction Negotiation (VCON) game (Yaoyuenyong et al., 2005), or they can only be played by a single player, such as the Virtual Construction Simulator (VCS) game (Nikolic et al., 2010).

\subsection{Characteristics of Project Complexity}

Project management (PM) is an endeavor to make something complex happen within budget, on time, and to specification through other people (Dh, 1987). Complexity is an important topic in PM research as projects have become more complex and failure in coping with complexity often leads to underperforming projects (Bakhshi et al., 2016). There are several factors that characterize project complexity. First, it is directly proportional to ambiguity or uncertainty (Cicmil and Marshall, 2005). Furthermore, complexity correlates positively with the number of project activities and decisions and with the amount of interactions required (Aritua et al., 2009, Bakhshi et al., 2016, Vidal and Marle, 2008).

\subsection{Gaps in Project Management Serious Games Literature}

Serious games application in PM has yielded many successful results. For example, the Incredible Manager game (Barros et al., 2006), a project planning and control game, has raised interest and skills in software PM. The Project Execution Game (Ofer and Amnon, 2007), which simulates risk events that occur in the project execution phase, is effective in teaching the unstructured area of project execution. A game of team communication and collaboration to confront participants with risk events that occur in project execution (Maratou et al., 2014) had a positive effect on improving collaboration among players.

Despite its success, there are several gaps in serious games application in PM education. First, there is a lack of serious games implementation in a multi-projects (program) context. Most PM games are made for a single-project scenario. What makes this an important gap is that most projects (i.e. $90 \%$ by value) are undertaken in a multi-projects scenario (Payne, 1995). 
Moreover, while complexity characterizes projects, it characterizes programs even more due to projects interacting with each other within the program (Aritua et al., 2009).

Another important gap is most PM games in the literature are single-player. The fact that only a small portion of multi-player games exist is worrying for two reasons. First, most singleplayer games allow players only to play as one role, which is as the project manager in most cases. In practice, however, there is more than one project manager in programs and there are other project roles (e.g. team members, sponsors, customers, environmental representatives, clients, contractors). Each stakeholder has an important role in completing the project (Karlsen, 2002). Second, since single-player games are dominant, communication between these stakeholders cannot be simulated. This is crucial as stakeholder communication is at the heart of PM. Failure to manage stakeholder communication could cause problems such as schedule and cost overrun, scope creep, and a lack of customer satisfaction (Naqvi and Aziz, 2011).

Furthermore, while the application of most PM serious games research is in project planning and control (e.g. Vanhoucke, Vereecke, \& Gemmel, 2005, Von Wangenheim, Savi, \& Borgatto, 2011, Ayk, 2012), none of the games has specifically addresses the issue of project crashing in both single-project and multi-projects scenarios. Project crashing (i.e. acceleration of projects by adding resources) is an important topic due to the fact that projects are almost always behind schedule (Gerk and Qassim, 2008).

\section{Serious Game Design Principles and PCG and PgCG Design}

The concept of game design is to model a real world problem into a game by collecting ideas for conceptual content and game process and to validate the game by testing it in the real world (Martin, 2000a). The subsequent section discusses the conceptual content of the games which is translated from design principles that are reviewed from the literature. The validation and testing are discussed in Sections 4 and 5.

\subsection{Clear Educational Goals}

The first principle in designing educational games (or serious games) is they should have clear educational goals (Von Wangenheim et al., 2011). Both PCG and PgCG are designed to help trainees in understanding the basic principles of project crashing (Pinto, 2009):

- Crashing is used to accelerate projects (or programs).

- Crash only activities on the critical path (i.e. both project critical paths and program critical paths). 
- Crash activities with the least crashing cost per day first.

- Crashing affects both direct and indirect costs of a project (or a program) which are the trade-offs that need to be considered in determining the most efficient crashing solution.

- When there is more than one critical path, parallel activities within the critical paths should be crashed simultaneously to reduce project duration.

In the $\mathrm{PgCG}$, there is an additional educational goal which is to train project teams to communicate with each other in order to identify the global optimum crashing solution (i.e. for the overall program) instead of the local optimum crashing solution (i.e. for individual projects). This design principle is translated by providing a chat box feature that enables teams (acting as project teams) to communicate with other project teams within the same program (see Figure 1).

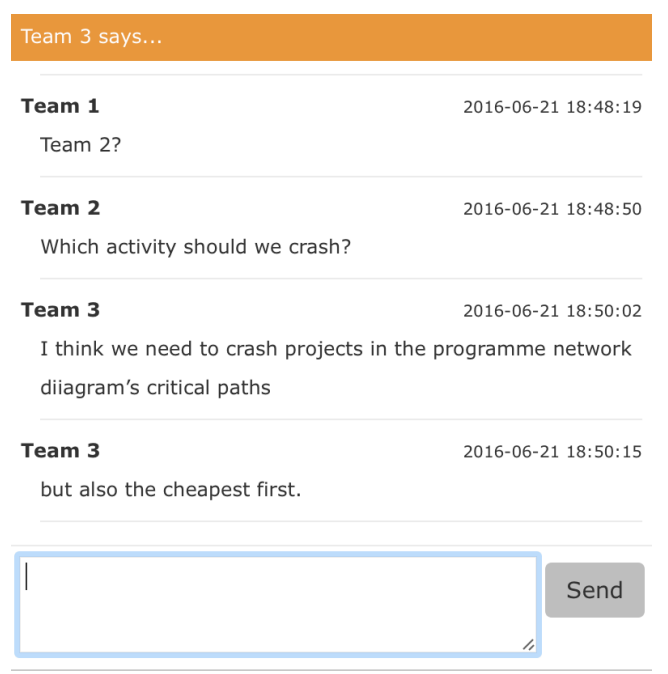

Figure 1. Chat box in Program Crashing Game (PgCG)

\subsection{Simple}

'Designing a simulation is not simple, but the simpler ones often work better' (Petranek, 1994). Making the game too complex to accurately model the reality may distract players with a morass of detail instead of keeping them focused on important educational aspects (Al-Jibouri and Michael J, 2001, Baird and Flavell, 1981). Nevertheless, it should not be too simple in that it loses attention to detail (Martin, 2000b). The general principle is therefore to design a game that is rich enough to encompass a variety of ideas needed to accomplish the educational goals but it should not be more complex than necessary. Both PCG and PgCG are designed based on this principle. In the PCG, players are only required to submit one decision per iteration (i.e. to select activity to be crashed for one day). They can see the impact of their decision on the same screen (see Figure 2). 


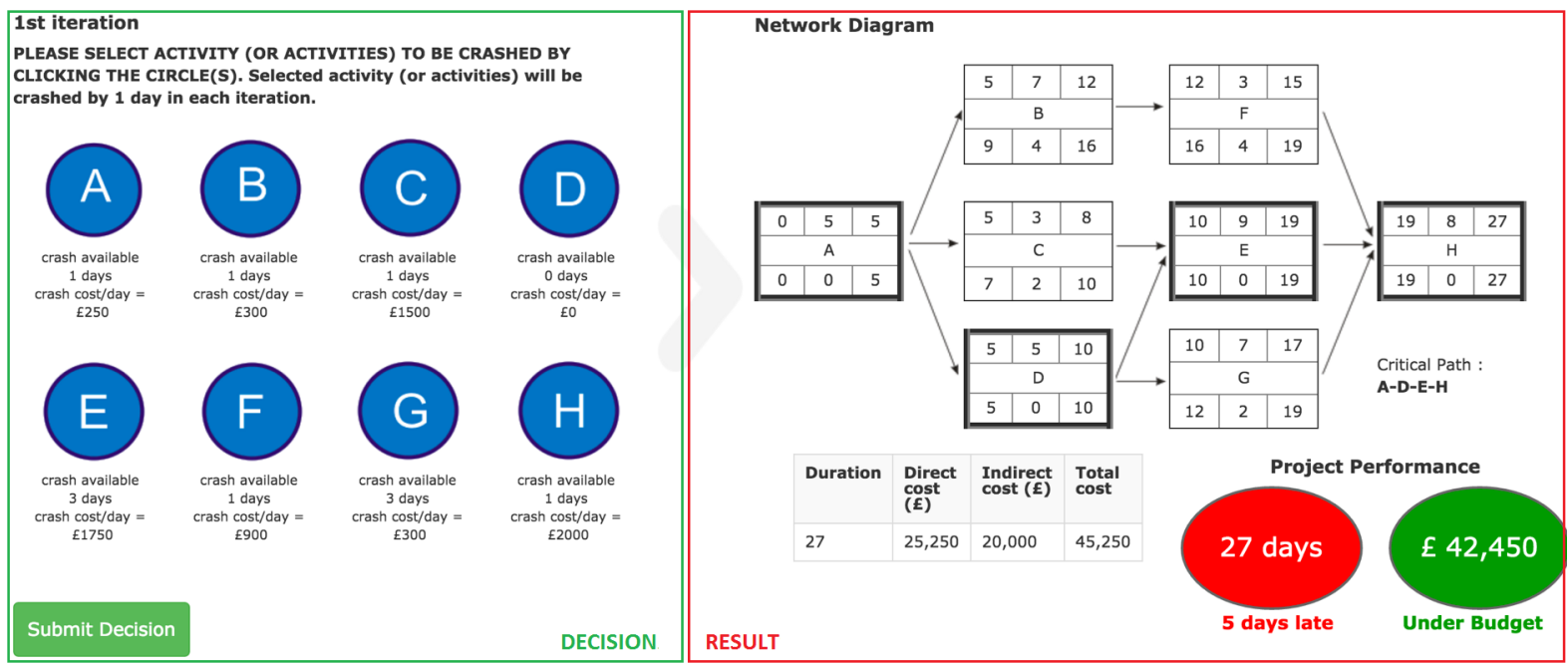

Figure 2. Decision and result view in Project Crashing Game (PCG)

In the PgCG, there is an additional element of complexity where the decision of each team affects the performance at both project and program levels. Nevertheless, as in the PCG, each team is only required to submit one decision per iteration.

\subsection{Motivating}

Good games motivate students to study and offer an enjoyable learning experience (Von Wangenheim et al., 2011). Motivation in gaming (Ayk, 2012) is an 'intrinsic impetus that drives players to get involved in a game and is therefore essential to ascertain players' engagement'. Ayk (2012) further suggests that motivation can be established in a game by considering three principles: flow, curiosity, and players' autonomy.

Flow is achieved when players are focused on their play and performance (Ayk, 2012). In PCG and $\mathrm{PgCG}$, this principle is translated by having a mechanism where feedback is provided after each decision. The network diagram and performance of the project and program are updated after each decision (see the 'result' box in Figure 2 for PCG feedback and Figure 3 for PgCG feedback).

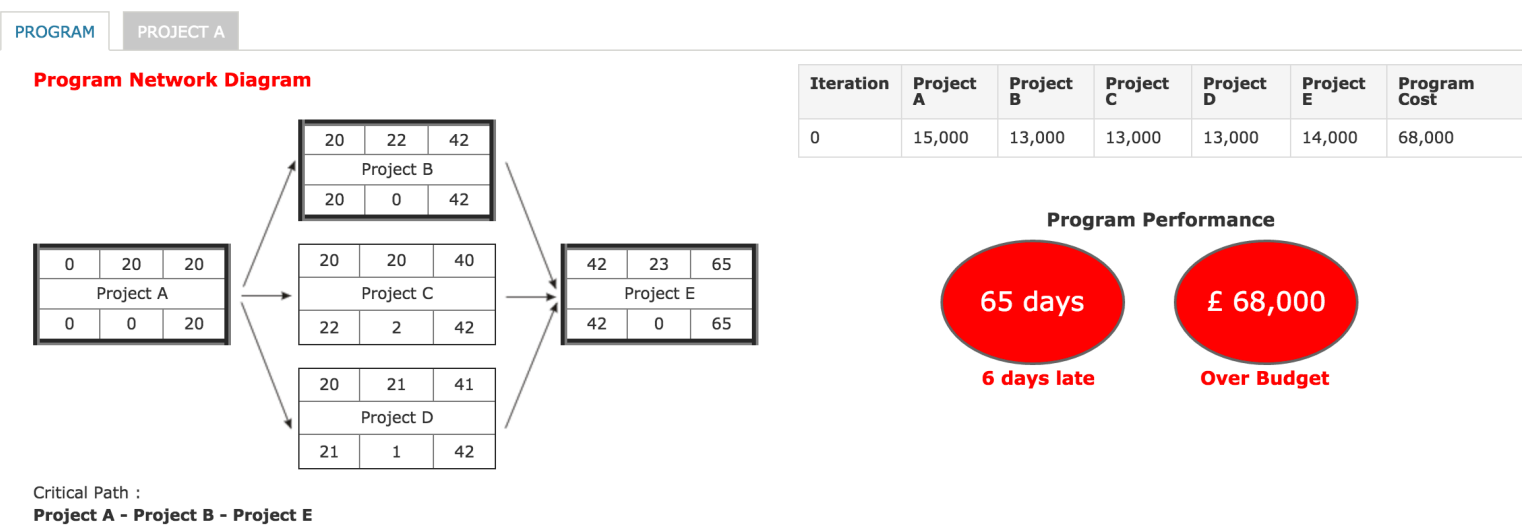




\section{Figure 3. Result view in PgCG}

Players are required to analyze the effect of each decision both on their project and on their program. In the PCG, the feedback is also expressed in the project sponsor's happy or angry reaction when correct or incorrect decisions are made (see Figure 4).

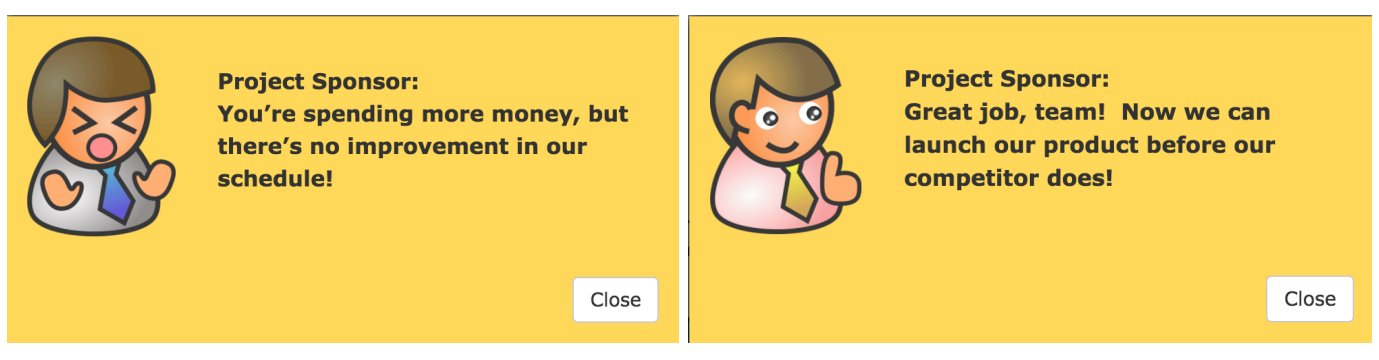

Figure 4. Examples of project sponsor's reaction (PCG)

Flow is also achieved if the game offers an optimum level of challenge to the players (Admiraal et al., 2011). This means that players find the game challenging but not too difficult. To facilitate learning, these challenges must be just outside the players' ability (Ayk, 2012). Furthermore, the challenge presented must also be progressive during the game as this encourages players to compete with themselves and improve their previous achievements (Inal and Cagiltay, 2007). Applying these principles, both PCG (i.e. a less complex game) and PgCG (i.e. a more complex game) are developed. They are played sequentially to make sure that players cope with a progressive level of challenge during the simulation. Players need to learn basic crashing principles from PCG first before attempting to play the more-difficult PgCG, otherwise, players can be frustrated in coping with the high level of difficulty of PgCG. Another aspect of 'challenge' is both games are time-constrained. In the PCG and PgCG, players are required to submit their decisions within 20 and 30 minutes respectively. The reason behind this is that serious games can simulate the pressure of time-constrained decision making (Chow, Woodford, \& Maes, 2011). This decision making pressure is one of the characteristics of a real-world project.

The second aspect that affects motivation is curiosity (Ayk, 2012). Curiosity can be classified as sensory curiosity which creates interest arousal in the senses, and cognitive curiosity which is affected by the semantic content of information. The first can be aroused by offering an emotional engaging fantasy while the latter can be developed through elements of surprise (e.g. new information at different stages of the game). In both PCG and PgCG, sensory curiosity is developed by showing a dynamic network diagram which is automatically updated after each decision, and by showing contrasting performance colors (i.e. green for 'on schedule' and 'on/under budget', and red for 'late' or 'over budget'). In the PgCG, the chat box feature could 
offer unexpected discussions (i.e. sensory curiosity) as each team must communicate with other teams to achieve the optimum result.

Players' autonomy is the third driver of motivation (Ayk, 2012). It is established when players view themselves as the initiators of their action. In the PCG and PgCG, this principle is applied by allowing players to initiate the projects, select activities to be crashed, finalize their decisions, view the simulation result, reset and exit the game. Players are also allowed to assign project managers and/or a program manager to accomplish the program objective in the PgCG.

\subsection{Realistic}

Another important principle is the game has to be realistic (Al-Jibouri and Mawdesley, 2001), which means that, while avoiding the risk of focusing on too much detail, it should be complex enough to model real-world projects. For instance, one major 'construction to services' company implemented a PM game in its recruitment process (Al-Jibouri et al., 2005). This company commented on the importance of the game's realism and how 'it enabled players to develop and show skills which could not be lectured'. This principle also aligns with the concept of situated learning which suggests that learning is more effective through a highly contextualized problem (or case study) rather than through a mere examination of inert factual data (Feinstein et al., 2002).

We apply the principle both in PCG and PgCG by introducing a contextualized case study where a new product development project (i.e. in the PCG case) or program (i.e. in the PgCG case) should be completed earlier due to a competition to be the first in the market. Players (i.e. project teams) are asked to complete the project (or program) earlier by crashing activities. As in real projects (or programs), they have a limited budget.

The other aspect of a realistic PM game is an element of competition (Baird and Flavell, 1981). This is translated in PgCG by having different projects that compete for a limited program budget. Teams within a program also compete with other teams who are assigned to crash another program. In PCG, this is translated by having each project team to compete with each other in achieving project objectives (see Figure 5).

\begin{tabular}{|l|l|l|l|l|}
\hline \multicolumn{2}{|l|}{ Team Performance } & Cost Performance & Time Performance & End Simulation \\
\hline No & Team & Under budget & On time & $22: 19: 37$ \\
\hline 1 & Team 1 & Under budget & 2 days late & $22: 20: 12$ \\
\hline 2 & Team 2 & Under budget & 4 days late & $22: 21: 44$ \\
\hline 3 & Team 3 & & & \\
\hline
\end{tabular}

Figure 5. Team performance ranking in PCG 


\subsection{Enabling Cyclical Learning}

Cyclical learning (Kolb, 1984), well-known as the Kolb cycle, emphasizes the acquisition of knowledge through experience through four successive phases:

- Concrete experience which consists of carrying out the tasks required to finish the game;

- Reflective observation which consists of reviewing actions / decisions and results;

- Conceptualization which consists of generalizing that experience into a new knowledge;

- Active experimentation which consists of translating the new knowledge into modified actions / decisions.

The concept of cyclical learning is the skeleton of both the PCG and PgCG (see Figure 6). Both games require players to carry out tasks (i.e. making decisions on selecting activity or activities to be crashed) and reflect on the outcome of their decision in each iteration by analyzing performance feedback (i.e. time and cost) and the updated network diagram. In the subsequent iteration, players have the opportunity to make a better decision based on their experience in the previous iteration (i.e. action and reflection). By playing the game several times, which is made possible by the 'reset game' option, players should be able to generalize project (or program) crashing concepts. This new knowledge should further enhance the quality of their decisions.

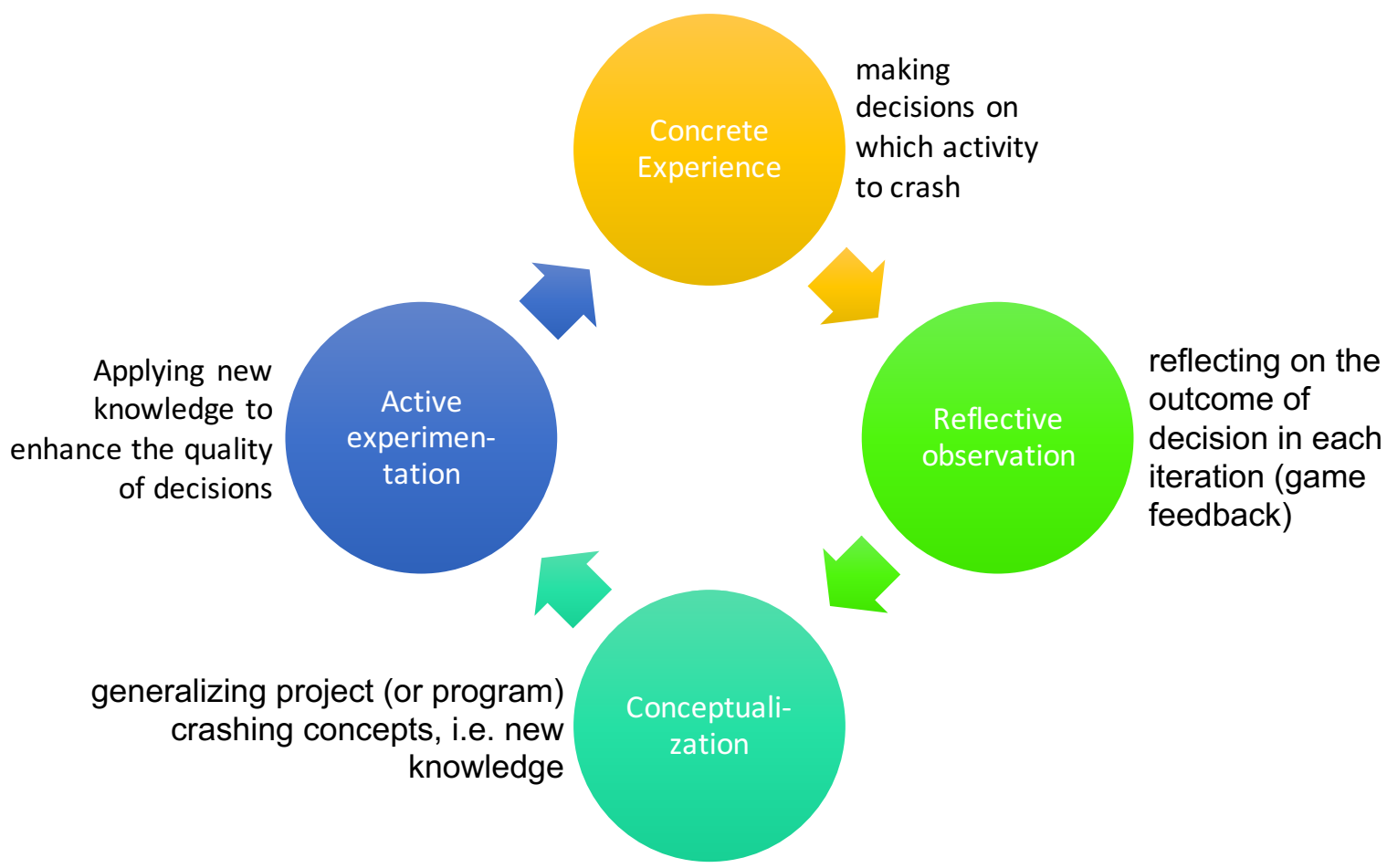


Figure 6. Translating Kolb learning cycle into PCG and PgCG design

Table 1 summarizes serious games design principles identified in the literature and how these are manifested in the design of PCG and PgCG. 
Table 1. Serious games design principles and their application in PCG and PgCG design

Serious Games Design $\quad$ PCG and PgCG Design
Principles
1. Have clear educational Both games have a clear learning objective: to teach basic goals project and program crashing principles. The PgCG also aims
(Von Wangenheim et al., to simulate project team communication to make collective 2011) optimal decisions.

2. Simple One decision in each iteration; straightforward feedback (Petranek, 1994, A1(result view).

Jibouri et al., 2005, Baird

and Flavell, 1981)

\begin{tabular}{ll}
\hline 3. Motivating & Flow: performance feedback after each decision; project \\
(Ayk, 2012) & sponsor's reaction (PCG), progressive challenge by playing a \\
less difficult game (i.e. PCG) before a more difficult one (i.e. \\
PgCG). Time-constrained decision making in both games. \\
Curiosity: dynamic network diagram; contrasting project and \\
program performance colors; elements of surprise in \\
communication via chat box and verbal communication \\
(PgCG). \\
Player's autonomy: teams have the authority to initiate the \\
projects, select activities to be crashed, finalize decisions, view \\
simulation result, reset and exit game. In the PgCG, teams can \\
also assign a program manager to manage the whole program \\
and a project manager for each project.
\end{tabular}

4. Realistic

(Al-Jibouri and

Mawdesley, 2001)

5. Enabling cyclical learning (Kolb, 1984)
A case study in the context of a new product development project (i.e. in PCG case) or program (i.e. in PgCG case); competition amongst teams.

Iteration, feedback, and 'reset game' option. 
To summarize, on the basis of the design principles outlined in Table 1 and previous game design discussions, the procedures (or game play) in PCG and PgCG are outlined as follows:

- A case study of a product development project crashing is provided to each team;

- Students are asked to crash (accelerate) the project in order to achieve goal of the game (i.e. new project cost and schedule objective);

- Students play the game in iterations and they can only crash one project activity per iteration;

- Each crashing decision in the iterations affects the overall performance of the project (i.e. actual cost, duration, network diagram);

- In the PCG, the feedback also takes form in project sponsors' reactions (i.e. angry and happy avatar reactions);

- In the PCG, students work within smaller project teams. In the PgCG, students work in the same project team as in the PCG but each team works together with other project teams within the same program group (i.e. 5 project teams per program group);

- Players are allowed to reset the game at any time;

- The game ends after 20 minutes in the PCG and after 30 minutes in the PgCG;

- To add an element of competition, each team's performance is shown on large screens which are visible to all teams.

\section{Learning Evaluation Method}

Kirkpatrick (1975) in Von Wangenheim et al. (2011) offers Four Levels of Evaluation, a widely known standardized framework to evaluate training and learning (see Table 2).

Table 2. Kirkpatrick's evaluation level (Kirkpatrick, 1975, Von Wangenheim et al., 2011)

\begin{tabular}{lll}
\hline Evaluation level & Description & Examples of tools and methods \\
\hline 1. Reaction & $\begin{array}{l}\text { How the learners felt } \\
\text { about their learning } \\
\text { experience }\end{array}$ & $\begin{array}{l}\text { Post-training surveys, happy-sheets; } \\
\text { feedback forms; verbal reactions }\end{array}$ \\
& $\begin{array}{l}\text { Knowledge or } \\
\text { capability improvement }\end{array}$ & $\begin{array}{l}\text { Pre- and post- tests; observations or } \\
\text { interviews }\end{array}$ \\
\hline
\end{tabular}




\begin{tabular}{lll}
\hline 3. Behavior & $\begin{array}{l}\text { Implementing learning } \\
\text { on the job }\end{array}$ & $\begin{array}{l}\text { Periodic observations and interviews to } \\
\text { assess change, relevance and sustainability } \\
\text { of change }\end{array}$ \\
\hline 4. Results & $\begin{array}{l}\text { Learners' learning } \\
\text { impact on their business } \\
\text { or environment }\end{array}$ & $\begin{array}{l}\text { Long-term post-training surveys; } \\
\text { observation as part of ongoing, sequenced } \\
\text { training and coaching over a period of time; } \\
\text { interviews (i.e. with peers and managers) }\end{array}$ \\
\end{tabular}

The evaluation level relevant to the scope of this research is level 1 (Reaction) as it only aims to initiate design and analyze students' reaction to different simulated project complexity levels.

In the previous section, five game design principles are identified:

- Clear educational goals

- Simple

- Motivating

- Realistic

- Enabling cyclical learning

These principles are then translated as evaluation criteria (see Table 3) where 15 variables (i.e. $V_{1}-V_{15}$ are proposed). In order to sharpen the evaluation, the third principle (i.e. motivation) is further decomposed based on the standardized ARCS model which describes factors that influence the motivation to learn (Keller, 1987). The ARCS model consists of: attention (A), relevance $(\mathrm{R})$, confidence $(\mathrm{C})$ and satisfaction $(\mathrm{S})$.

Table 3. PCG and PgCG evaluation criteria

Game principles Questionnaire questions:

Assess your experience when playing the game.

$(1=$ Strongly Disagree; 7 = Strongly Agree $)$

1.Clear $\quad$ 'I understand clearly the lessons of playing this game.' $\left(V_{1}\right)$
educational
goals


2. Simple

(1)

$\sqrt{2}$ understanding of the game.' $\left(V_{2}\right)$ *

- 'It was difficult for me to understand how to play the game.' $\left(V_{3}\right)$
Attention (A):

(Von

Wangenheim et al., 2011)
- 'The design of the game is attractive.' $\left(\boldsymbol{V}_{4}\right)$

- 'Throughout the exercise, the game has kept my attention.' $\left(V_{5}\right)$ Relevance (R):

- 'The content of the game is relevant to my interests.' $\left(\boldsymbol{V}_{6}\right)$

- 'The content of the game is connected to my prior knowledge.' $\left(V_{7}\right)$

Confidence (C):

- 'It was easy for me to understand this game.' $\left(\boldsymbol{V}_{\mathbf{8}}\right)$

- 'Advancing through this game, I felt confident that I was learning.' $\left(V_{9}\right)$

Satisfaction (S):

- 'I am satisfied since I have learned important lessons from playing this game.' $\left(V_{\mathbf{1 0}}\right)$

- 'I know I can apply the lessons I learned from this game in the future.' $\left(V_{11}\right)$
4. Practical and realistic
- 'The lessons from playing this game can be applied in project management practice.' $\left(\boldsymbol{V}_{\mathbf{1 2}}\right)$

- 'I felt like I was in a real project when playing the game.' $\left(\boldsymbol{V}_{\mathbf{1 3}}\right)$

- 'Passing through the game, I learned where my mistakes were.' 5. Enabling cyclical learning $\left(V_{14}\right)$

- 'Passing through the game, there was enough feedback for me to improve my performance in each iteration.' $\left(\boldsymbol{V}_{\mathbf{1 5}}\right)$ 


\section{Game Development, Experiment and Results}

\subsection{Game Development}

The game development project was completed in five stages:

a) Identifying serious games design principles and translating these into the design concept of both games;

b) Building a mock-up of the games and gaining initial approval from the course leader;

c) Developing and testing the engine of the games (i.e. software program, database, and user interface);

d) Identifying bugs (errors) and other potential improvement through a pilot study;

e) Improving and finalizing the games.

The first stage is already discussed in Section 3. The next stages are technical steps which were conducted to ensure that the design principles and game concepts identified in the first stage are translated accurately into the infrastructure of both games.

The underlying technology of both games is computer-based. Computer-based games have the advantage in that they can automatically record the events and decisions taken. These are necessary for debriefing and analysis purposes (Martin, 2000). In addition, unlike in the paperbased format, players focus on decision making and are released from tedious calculations.

\subsection{Experiment}

The games were introduced to MSc Management of Projects students of the University of Manchester. Data are collected from 285 students who participated in the experiment. Most of the respondents (i.e. 230 students) do not have any work experience in PM, 47 students have less than 5 years' experience, and 8 have at least 5 years of experience. Both games (i.e. PCG and $\mathrm{PgCG}$ ) were played by the students. They were then asked to provide their feedback based on the evaluation criteria outlined in the previous section.

A quantitative approach is selected as it serves best in identifying tendencies (Malhotra and Peterson, 2006) in the form of similarities and differences in students' reactions on the less and more complex PM games on the basis of the identified variables in Table 3. Identifying these tendencies is crucial to achieve the aim of our research, which is to compare students' learning experience on games with different project complexity levels. This approach aligns with the nature of our study as a research project (i.e. analyzing the effect of different simulated project 
complexity levels on students' learning experience) and not just as an evaluation project (i.e. evaluating the effectiveness of each game).

\subsection{Data Analysis and Results}

To investigate whether or not different complexity levels of the games (i.e. PCG and PgCG) affect students' learning experience, a test of hypothesis of different between two means was performed on each variable in Table 3 where:

$$
\begin{aligned}
& H_{0}: \mu_{d}=0 \\
& H_{a}: \mu_{d} \neq 0
\end{aligned}
$$

$H_{0}$ : there is no difference between students' learning experience on PCG and PgCG (i.e. measured by each variable in Table 3). In this hypothesis, $\mu_{d}$, the difference between the two means, is equal to 0 .

$H_{a}$ : there is a difference between students' learning experience on PCG and PgCG (i.e. measured by each variable in Table 3 ). In this hypothesis, $\mu_{d}$, the difference between the two means, is not equal to 0 .

The paired t-test method (Bausell and Li, 2002) is selected to test the hypothesis as both samples are dependent (i.e. different games were tested on the same group of students). The normal distribution assumption for the population of differences is not needed due to the large sample size (McClave, 2001). IBM SPSS Version 22 is applied as a data analysis tool. The results are then double-checked by performing a manual paired t-test procedure. Table 4 displays the result of the hypothesis testing on each variable.

\begin{tabular}{|c|c|c|c|c|c|c|c|c|c|c|c|c|c|c|c|}
\hline $\begin{array}{l}\text { Design } \\
\text { principles } \\
\text { variable }\end{array}$ & $V_{1}$ & $V_{2}$ & $V_{3}$ & $V_{4}$ & $V_{5}$ & $V_{6}$ & $V_{7}$ & $V_{8}$ & $V_{9}$ & $V_{10}$ & $V_{11}$ & $V_{12}$ & $V_{13}$ & $V_{14}$ & $V_{15}$ \\
\hline $\begin{array}{l}\text { Test statistic } \\
\text { (t score) }\end{array}$ & -0.066 & -2.426 & -0.915 & -2.197 & -0.486 & -2.271 & 2.288 & 0.585 & 2.37 & -0.308 & -1.933 & -2.347 & -8.376 & 2.602 & 0.989 \\
\hline $\begin{array}{l}\text { Sig. (2- } \\
\text { tailed) }\end{array}$ & 0.947 & 0.016 & 0.361 & 0.029 & 0.627 & 0.024 & 0.023 & 0.559 & 0.018 & 0.758 & 0.054 & 0.020 & 0.000 & 0.010 & 0.324 \\
\hline $\begin{array}{l}\text { Hypothesis } \\
\text { test result }\end{array}$ & $\begin{array}{c}\text { accept } \\
\text { Ho }\end{array}$ & $\begin{array}{c}\text { reject } \\
\text { Ho }\end{array}$ & $\begin{array}{c}\text { accept } \\
\text { Ho }\end{array}$ & $\begin{array}{c}\text { reject } \\
\text { Ho }\end{array}$ & $\begin{array}{c}\text { accept } \\
\text { Ho }\end{array}$ & $\begin{array}{c}\text { reject } \\
\text { Ho }\end{array}$ & $\begin{array}{c}\text { reject } \\
\text { Ho }\end{array}$ & $\begin{array}{c}\text { accept } \\
\text { Ho }\end{array}$ & $\begin{array}{c}\text { reject } \\
\text { Ho }\end{array}$ & $\begin{array}{c}\text { accept } \\
\text { Ho }\end{array}$ & $\begin{array}{c}\text { accept } \\
\text { Ho }\end{array}$ & $\begin{array}{c}\text { reject } \\
\text { Ho }\end{array}$ & $\begin{array}{c}\text { reject } \\
\text { Ho }\end{array}$ & $\begin{array}{c}\text { reject } \\
\text { Ho }\end{array}$ & $\begin{array}{c}\text { accept } \\
\text { Ho }\end{array}$ \\
\hline $\begin{array}{l}\text { More } \\
\text { associated } \\
\text { with }\end{array}$ & - & PgCG & - & PgCG & - & PgCG & PCG & - & PCG & - & - & PgCG & PgCG & PCG & - \\
\hline
\end{tabular}

Table 4. Hypothesis test (paired t-test) result on each evaluation variable

At 95\% confidence (significance level $\alpha=0.05$ ), the result shows that students perceive that their learning experience with PCG and PgCG can be differentiated by eight game design principle variables: $\boldsymbol{V}_{2}, \boldsymbol{V}_{\mathbf{4}}, \boldsymbol{V}_{\mathbf{6}}, \boldsymbol{V}_{\mathbf{7}}, \boldsymbol{V}_{\mathbf{9}}, \boldsymbol{V}_{\mathbf{1 2}}, \boldsymbol{V}_{\mathbf{1 3}}$, and $\boldsymbol{V}_{\mathbf{1 4}}$. Students tend to identify $\boldsymbol{V}_{\mathbf{2}}, \boldsymbol{V}_{\mathbf{4}}$, 
$\boldsymbol{V}_{\mathbf{6}}, \boldsymbol{V}_{\mathbf{1 2}}$, and $\boldsymbol{V}_{\mathbf{1 3}}$ as more associated with PgCG than with PCG. On the other hand, $\boldsymbol{V}_{\mathbf{7}}, \boldsymbol{V}_{\mathbf{9}}$, and $\boldsymbol{V}_{\mathbf{1 4}}$. are perceived as more aligned to PCG than with PgCG.

\section{Findings and Discussion}

The results outlined in the previous section suggests that when the project complexity level is increased (i.e. from PCG to PgCG), students tend to agree that the simulated project becomes more realistic:

- the lessons can be applied in PM practice $\left(\boldsymbol{V}_{\mathbf{1 2}}\right)$,

- they felt like they were in a real project when playing the game $\left(\boldsymbol{V}_{\mathbf{1 3}}\right)$.

This aligns with Thomas' and Mengel's (2007) notion that, in the real life, projects are characterized by complexities. The 'realistic' design principle applied in both games clearly distinguishes the two games in question. In the PgCG, the collaborative setting of the game forces players to learn real-world PM skills that "could not be lectured" (Al-Jibouri et al., 2005), such as communication and leadership skills. These skills are important in PM practice as 'about $90 \%$ of the time in a project is spent on communication' (Rajkumar, 2010). The element of competition in the PCG and PgCG design could also have effect on how both games are perceived in terms of realism (Baird and Flavell, 1981). In the PCG, players only compete externally. The PgCG, on the other hand, is more realistic since, as in actual projects, project teams compete not only externally (i.e. with other program teams), but also internally (i.e. with other project teams in the same program team). Another factor that could explain why students perceive PgCG as more realistic is its larger scale (i.e. in terms the number of activities, interactions, and decisions required in the game). These are key characteristics that resembles complex projects (Vidal and Marle, 2008, Aritua et al., 2009).

The other advantage of increased complexity level in PgCG is that students perceive its content as more relevant to their interests compared to that of the less complex game $\left(\boldsymbol{V}_{\mathbf{6}}\right)$. In addition, students tended to perceive the complex PM game design as more attractive than the simpler one $\left(\boldsymbol{V}_{4}\right)$. The collaborative setting and features in the PgCG (e.g. chat box, project manager and/or program manager assignment) offer players with more opportunities to communicate with each other. Based on our observation, players perceive these as more attractive and interesting compared to the single-player setting and limited features in the PCG. These are motivational features that improve players' attention and interest when playing the game (Ayk, 2012, Keller, 1987). 
Too much information in the more complex PM game can confuse students' understanding of the game $\left(\boldsymbol{V}_{\mathbf{2}}\right)$. Although it looks like a disadvantage, this represents the reality in PM practice where the "right information, at the right time, in the right format" can never be reached (Strait and Dawson, 2006). In the PCG, players only deal with the information within their own individual project (e.g. project cost, time, budget, schedule, activities, and network diagram). In the PgCG, the amount of information that needs to be considered is at least five times more than in the PCG as each program consists of five projects. In projects, there are two types of complexity, namely "complexity of faith" and "complexity of fact" (Geraldi and Adlbrecht, 2007). The first signifies the effect of levels of uncertainty on project complexity (e.g., coping with new situations, developing something new, or when historical data is limited). The latter, on the other hand, is determined by the amount of interrelated data and information which need to be analyzed. Students' reaction on $\boldsymbol{V}_{2}$ clearly indicates "the complexity of fact" which makes the PgCG perceived as more complicated compared to the PCG.

With the less complex game (PCG), learners tend to perceive that the content is more relevant to their prior knowledge $\left(\boldsymbol{V}_{\mathbf{7}}\right)$ and they feel more confident that they were learning $\left(\boldsymbol{V}_{\mathbf{9}}\right)$. This could be explained by the fact that most of the respondents are students with no or limited PM practical experience. Hence, they need to learn the basic concepts offered in the less complex game (PCG) first. This is consistent with the notion that games can be useful in reinforcing basic concepts (Earl, 1999).

Students also tend to agree that the PCG provides better feedback for them to improve their performance in each iteration $\left(\boldsymbol{V}_{\mathbf{1 4}}\right)$. This could be explained by the fact that there is no feedback from project sponsors (e.g. angry or happy avatar reactions in the PgCG as in the PCG). This result highlights the importance of direct feedback after making each decision in each iteration, particularly in games that require coordinated behavior such as the PgCG (Weber, 2003).

Our study complements existing works (Raia, 1966, Wolfe, 1978) which study the effect of game complexity on learning experience. The findings proposed in this study do not align with Raia's (1966) findings which suggest no significant differences in terms of students' learning experience and motivation when playing games with different complexity levels. Unlike in Raia's (1966) work, we breakdown learning experience and motivation factors into more detailed learning evaluation variables (e.g. realism, attention, confidence). This provides a more comprehensive perspective on the effect of game complexity levels on learning experience and motivation. We also expand Raia's (1966) limited complexity dimension by 
inserting interactions between teams in our game design, which is a key feature in PM practice. Furthermore, the findings of our study align with Wolfe's (1978) findings which suggest that higher complexity in games is more associated with realism and comprehensiveness in decision making.

\section{Conclusions and Implications}

The findings of this study highlight that students' learning experience in project management serious games is affected by the complexity of the simulated project. The more complex the project is (i.e. in terms of communication effort needed, and number of projects, activities, teams, and decisions needed to be made), the more realistic the game becomes. This also means that the lessons of the game are perceived as more applicable and its content is perceived as more relevant to students' interests. Complex games are important in project management practice since delivering education that enables students to cope with the actual project complexity is an important gap that needs to be addressed. Nevertheless, the less complex one should not be neglected, particularly to teach basic project management principles to those with minimum or no practical experience. A reasonable approach is to apply both the less and the more complex games instead of selecting one of them, as they complement each other.

We also find that design plays a key role in differentiating game complexity levels and students' learning experience. As shown in our study, by increasing the number of decisions, activities, and projects, and "forcing" the players to collaborate with each other, PM games can be made more complex, hence more realistic for students. Avatar feedback (in our case: project sponsors' angry and happy reactions) is an important feature to help students to learn from their mistakes. Additional competitive factors (in our case: internal and external competition) could add more realism into the games. Collaborative features (in our case: chat box, project and/or program managers assignment) could improve players' learning motivation as they make the game more attractive and interesting.

The findings proposed in our work have potential implications on several entities: PM body of knowledge (e.g. PMBoK), PM game designers, researchers and educators. The issue with PMBoK (PMI, 2017) is it recognizes the need for practical training but offers little explanation on how this could be achieved. This study offers a concrete solution in the design of PM serious games which are experiential learning methods that can help project participants to cope with the actual complexity in projects. For PM serious games designers and researchers, this study offers an interesting insight into complexity-based game design. We suggest game designers 
and researchers consider complexity levels in their game design and evaluation since these could affect learning experience in multiple ways as our study suggests. We advise PM educators to be more flexible in their teaching method. Some of PM concepts could and should be taught via traditional classroom methods. However, serious games should also be considered as they can be used effectively to reinforce these concepts (as in the case of PCG), and to provide collaborative learning experience in coping with more complex PM problems (as in the case of $\mathrm{PgCG}$ ).

\section{Limitations}

The research can be expanded by inserting other factors of project complexity into the games (e.g. unexpected delays, change requests from stakeholders). This enables further research to examine the effect of each complexity factor on students' learning experience. Another limitation of this research is it only examines short term students' reaction (i.e. perceptual measures) after playing the games. While perceptual measures are often applied reliably in social science study, there are limitations in using a single measurement method to evaluate training (McCreery, 2003). Pre-test and post-test, periodic observations, and long-term posttraining surveys may be needed to measure learning effectiveness, particularly in terms of students' ability to retain and apply their knowledge. However, the current approach is sufficient to achieve the aim of this research, which is to design and evaluate the games with different complexity levels. Furthermore, further research which applies a qualitative method may provide deeper insights on how students perceive the design of both games. This method can also be complemented by a quantitative approach which specifically analyzes the effect of each design principle on students' learning experience. Finally, the effect of other factors such as test subjects' gender, age, and game experience on learning experience are not measured and analyzed in this study. To test the effect of these factors, a replication of the experiment should be conducted to multiple groups with different backgrounds and demographic data.

\section{Acknowledgements}

The authors gratefully acknowledge the Indonesia Endowment Fund for Education (Lembaga Pengelola Dana Pendidikan / LPDP) for sponsoring this research. LPDP provides a PhD scholarship for the main author which makes this research possible. This sponsorship does not affect the process and outcome of the research. There is no conflict of interest in the research. 


\section{References}

ADMIRAAL, W., HUIZENGA, J., AKKERMAN, S. \& TEN DAM, G. 2011. The concept of flow in collaborative game- based learning. Computers In Human Behavior, 27, 1185-1194.

AL-JIBOURI, S. 2005. The use of a simulation model as a game for teaching management of projects in construction. The International journal of engineering education., 21, 1195.

AL-JIBOURI, S., MAWDESLEY, M., SCOTT, D. \& GRIBBLE, S. 2005. The use of a simulation model as a game for teaching management of projects in construction. International Journal of Engineering Education, 21, 1195.

AL-JIBOURI, S. H. \& MICHAEL J, M. 2001. Design and experience with a computer game for teaching construction project planning and control. Engineering, Construction and Architectural Management, 8, 418-427.

ARITUA, B., SMITH, N. J. \& BOWER, D. 2009. Construction client multi-projects - A complex adaptive systems perspective. International Journal of Project Management, 27, 7279.

AYK, C. 2012. An Exploratory Study of Game-based M-learning for Software Project Management. Journal of universal computer science, 18, 1933.

BAIRD, A. N. \& FLAVELL, R. 1981. A project management game. Computers \& Education, 5, 118.

BAKHSHI, J., IRELAND, V. \& GOROD, A. 2016. Clarifying the project complexity construct: Past, present and future. International Journal of Project Management, 34, 1199-1213.

BARROS, M. D. O., DANTAS, A. R., VERONESE, G. O. \& WERNER, C. M. L. 2006. Model- driven game development: experience and model enhancements in software project management education. Software Process: Improvement and Practice, 11, 411-421.

BAUSELL, R. B. \& LI, Y.-F. 2002. The paired t-test. In: BAUSELL, R. B. \& LI, Y.-F. (eds.) Power Analysis for Experimental Research: A Practical Guide for the Biological, Medical and Social Sciences. Cambridge: Cambridge University Press.

CALDERÓN, A. \& RUIZ, M. 2015. A systematic literature review on serious games evaluation: An application to software project management. Computers and Education, 87, 396422.

CICMIL, S. \& MARSHALL, D. 2005. Insights into collaboration at the project level: complexity, social interaction and procurement mechanisms. Building Research \& Information, 33, 523-535.

CONNOLLY, T. M., BOYLE, E. A., MACARTHUR, E., HAINEY, T. \& BOYLE, J. M. 2012. A systematic literature review of empirical evidence on computer games and serious games. Computers \& Education, 59, 661-686.

DANTAS, A. R., DE OLIVEIRA BARROS, M. \& WERNER, C. M. L. A Simulation-Based Game for Project Management Experiential Learning. 2004 2004. 24.

DEMPSEY, J. V., LUCASSEN, B. \& RASMUSSEN, K. 1996. The instructional gaming literature: Implications and 99 sources, University of South Carolina, College of Education.

$\mathrm{DH}, \mathrm{H}$. 1987. Management: Principles and practices.

EARL, S. 1999. Facilitating Student Learning: A Practical Gude for Tertiary-Level Teachers, Penerbit UTM.

FEINSTEIN, A. H., MANN, S. \& CORSUN, D. L. 2002. Charting the Experiential Territory: Clarifying Definitions and Uses of Computer Simulation, Games, and Role Play. Journal of Management Development, 21, 732-44. 
GERALDI, J. G. \& ADLBRECHT, G. On faith, fact, and interaction in projects. 2007. Project Management Institute.

GERK, J. E. V. \& QASSIM, R. Y. 2008. Project Acceleration via Activity Crashing, Overlapping, and Substitution. Engineering Management, IEEE Transactions on, 55, 590-601.

HENDRIX, M., AL-SHERBAZ, A. \& BLOOM, V. 2016. Game Based Cyber Security Training: are Serious Games suitable for cyber security training? : International Journal of Serious Games.

INAL, Y. \& CAGILTAY, K. 2007. Flow experiences of children in an interactive social game environment. British Journal of Educational Technology, 38, 455-464.

KARLSEN, J. T. 2002. Project Stakeholder Management. Engineering Management Journal, 14, 19-24.

KELLER, J. M. 1987. Development and Use of the ARCS Model of Motivational Design. Journal of Instructional Development, 10, 2-10.

KIRKPATRICK, D. L. 1975. Evaluating training programs, Tata McGraw-Hill Education.

KOLB, D. A. 1984. Experiential learning : experience as the source of learning and development, Englewood Cliffs, N.J. ; London, Englewood Cliffs, N.J. ; London : Prentice-Hall.

MALHOTRA, N. K. \& PETERSON, M. 2006. Basic marketing research: a decision-making approach, Pearson/Prentice Hall.

MARATOU, V., CHATZIDAKI, E. \& XENOS, M. 2014. Enhance learning on software project management through a role- play game in a virtual world. Interactive Learning Environments, 1-19.

MARTIN, A. 2000a. The design and evolution of a simulation/game for teaching information systems development. Simulation and gaming, 31, 445-463.

MARTIN, A. 2000b. A simulation engine for custom project management education. International Journal of Project Management, 18, 201-213.

MCCLAVE, J. T. 2001. Statistics for business and economics, Upper Saddle River, NJ, Upper Saddle River, NJ : Prentice Hall.

MCCREERY, J. K. 2003. Assessing the value of a project management simulation training exercise. International Journal of Project Management, 21, 233-242.

NAQVI, I. \& AZIZ, S. 2011. The impact of stakeholder communication on project outcome. African Journal of Business Management, 5, 5824-5832.

NIKOLIC, D., LEE, S., MESSNER, J. I. \& ANUMBA, C. 2010. The virtual construction simulator: Evaluating an educational simulation application for teaching construction management concepts. CIB W78 2010: 27th International Conference. Cairo, Egypt: ITC Digital Library.

OFER, Z. \& AMNON, G. 2007. Project execution game ( $P E G)$ : training towards managing unexpected events. Journal of European Industrial Training, 31, 495-512.

PAYNE, J. H. 1995. Management of multiple simultaneous projects: a state-of-the-art review. International Journal of Project Management, 13, 163-168.

PETRANEK, C. 1994. A Maturation in Experiential Learning: Principles of Simulation and Gaming. Simulation \& gaming, 25, 513-523.

PINTO, J. K. 2009. Project management : achieving competitive advantage, Upper Saddle River, N.J. ; Harlow, Upper Saddle River, N.J. ; Harlow : Pearson Education.

PMI 2017. A guide to the project management body of knowledge : (PMBOK Guide), Newtown Square, Newtown Square : Project Management Institute. 
RAIA, A. P. 1966. A Study of the Educational Value of Management Games. The Journal of Business, 39, 339-352.

RAJKUMAR, S. 2010. Art Of Communication In Project Management. Project Management Institute.

STRAIT, C. \& DAWSON, R. 2006. Too much information. PM Network.

THOMAS, J. \& MENGEL, T. 2008. Preparing project managers to deal with complexity Advanced project management education. International Journal of Project Management, 26, 304-315.

VIDAL, L.-A. \& MARLE, F. 2008. Understanding project complexity: implications on project management. Kybernetes, 37, 1094-1110.

VON WANGENHEIM, C. G., SAVI, R. \& BORGATTO, A. F. 2011. DELIVER! - An educational game for teaching Earned Value Management in computing courses. Information and Software Technology.

WEBER, R. A. 2003. 'Learning' with no feedback in a competitive guessing game. Games and Economic Behavior, 44, 134-144.

WOLFE, J. 1978. The effects of game complexity on the acquisition of business policy knowledge. Decision Sciences, 9, 143-155.

YAOYUENYONG, C., HADIKUSUMO, B. H. W., OGUNLANA, S. O. \& SIENGTHAI, S. 2005. Virtual construction negotiation game-an interactive learning tool for project management negotiation skill training. 2 . 